\title{
A Methodical Search of Web Content Accessibility for Visual Disabled People
}

\author{
M. Nagaraju, Priyanka Chawla
}

\begin{abstract}
The Internet has revolutionized and became a major option to obtain information. The complete faith of any individual or organization depends on the official website they are using. Therefore, it is the duty of organizations to provide a website design environment in such a way that even a visually disabled person can access the content without any issues. In view of a website content accessibility importance, the present article has reviewed some of the literature to study how the web content accessibility has been done, what architecture they have used, what suggestions they made and the limitations of those studies. The article also studied only the literature that considered W3C WCAG 2.0 guidelines for website evaluation. The main objective of the present article is to summarize the observations of the existing literature and identify the influencing factors on the quality of a website. The present work also studied the various approaches that are implemented by the researchers to evaluate the website quality. Finally, a comparative analysis was made and determined the outcomes as results and made a few discussions to identify some other technical and non-technical barriers if any.
\end{abstract}

Keywords: WCAG 2.0, W3C, Website Accessibility, Website Content, Website Design.

\section{INTRODUCTION}

The advancement of internet modern technologies is a sensation with a routine adjustment as well as coming to be much more conscious all the needs and assumptions of the customers in this contemporary globe. To balance a website, the website development must be performed such that the content is organized based on the user interface and their degree of accessibility levels. It is far better to implement a user-specific design procedure while creating a website to ensure that it may satisfy the customer needs with no problems. The purpose of this work can be satisfied with a substantial method by specifying the website viewers and a couple of common factors preferred by both individuals and internet programmers. To balance a website, we require internet growth as if maybe well-structured, as well as a user, interface with the user expectation level. The design should focus on exposure, readability, language by taking the user

Revised Manuscript Received on August 30, 2019.

* Correspondence Author

M Nagaraju*, Department of Computer Science and Engineering, Lovely Professional University, Phagwara, Punjab, India. Email: nagaraju.41800497@lpu.in

Dr. Priyanka Chawla, Department of Computer Science and Engineering, Lovely Professional University Phagwara, Punjab, India. Email: priyankachawla.cse@gmail.com

(c) The Authors. Published by Blue Eyes Intelligence Engineering and Sciences Publication (BEIESP). This is an open access article under the CC BY-NC-ND license (http://creativecommons.org/licenses/by-nc-nd/4.0/) profiles into consideration. The purpose is to study the review that can met the substantial strategy by specifying the website target audience by preferring some variables preferred by both individuals and internet programmers.

From the internet designer's view, taking care of the website growth calls for understanding the hosting internet server, markup languages while developing client and server-oriented programs, website design, internet browser compatibility at the client-end. From the customer's view, the top quality of a website depends on its clarity, functionality, and fulfillment of user needs. As the variety of domain names are boosting day-by-day and great deals of details can be offered to the individuals in various sort of solutions. The modern-day social media infrastructure suggests on the factor that every solution ought to be made readily available and accessed by every individual and by a visually impaired. This has made vast advantages to them at their location with no problems. However, W3C has come with specific standards that can be adhered to and make sure it is not so complicated to accessibility for visually impaired customers while accessing the internet content. The main demand of an internet programmer is to create a website that can resolve the objective of the user while content accessing. Several usability elements and complexity metrics were considered while assessing the high quality of the website regarding accessibility. It is so necessary for every website designer to ensure that the website is quickly available for every degree of individuals regardless of language, education, learning, and despite their age group. It is additionally needed to review a website regarding accessibility also by the individuals with various impairments. Numerous techniques have been developed in the direction of the website analysis throughout the last years. They have adhered to informative-oriented analysis method to establish a site as per the demands of an individual and adhered to the standards of W3C. Throughout the analysis procedure, a listing of internet quality elements is recognized with the reference to website high quality. Numerous constraints included into consideration are precision, flexibility, analysability, complexity in computer animation, website framework, high-quality content, 
individual contentment in look, broken web links, internet browser relevant concerns, design templates, compatibility, download time and others. The research study has been performed to recapitulate the existing research like web-related training evaluation in creating a website with a requirement of enlighten concepts and techniques which pertain to the accessibility standards WCAG 2.0 advised by W3C. This article has examined documents released regarding website high-quality analysis and website accessibility standards. The review is arranged by a regular structure and based upon the website URL as a key resource for future study tasks. The interior URLs, as well as the website design top quality examination, are thought about for more interactive activities. Finally, the process of review has started with an objective to evaluate a website based on its accessibility, to identify what factors or measures influencing the quality and determine the need for website optimization.

\section{REVIEW OF LITERATURE}

\section{A. Purpose of Research}

This section targets to review and summarize the present state of the art in selecting the criteria for website accessibility evaluation with respect to W3C guidelines recommended or simply WCAG 2.0 guidelines. The entire methodology is continued by reviewing the solutions of the questions below:

(i) Is there any significance of developing a free accessible website?

(ii) What are the various factors that can impact the accessibility of a website?

(iii) What is the impact of existing approaches while evaluating website quality?

(iv) How can we assess the website quality based on WCAG 2.0 guidelines?

\section{B. Search Standard}

Based upon the inquiries mounted for examination, a collection of basic synonyms, as well as keywords, were specified as search strings. Being website assessment is a flaming principle in the website development process and ignoring the articles evaluation in the search.

Table-I. Search Phrases

\begin{tabular}{|c|c|}
\hline \multicolumn{2}{|c|}{ Phrases } \\
\hline Website Accessibility & Web Content \\
\hline Accessibility Evaluation & Website Assessment \\
\hline Website Content & $\begin{array}{c}\text { Automation Tools for } \\
\text { Evaluation }\end{array}$ \\
Website Evaluation \\
\hline
\end{tabular}

\section{Information Sources}

The concept reviewed were arranged with different perspectives of individual models contributed by different authors were considered.

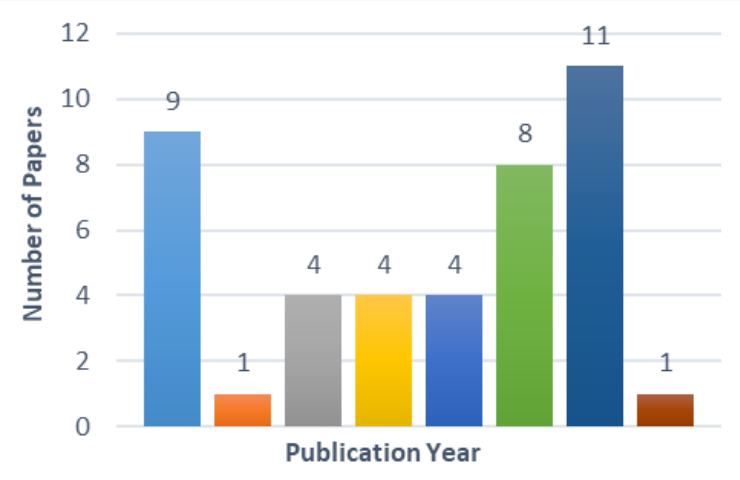

| Upto 2010 a 2011 | 2013 | 2014 | 2015 | 2016 | 2017 | 2018

Fig. 1. Papers selected by year of publication

Table-II. Clustering of Major Studies by proposed research questions

\begin{tabular}{|c|c|}
\hline $\begin{array}{l}\text { Research } \\
\text { Questions }\end{array}$ & Major Studies \\
\hline $\begin{array}{l}\text { Significance of } \\
\text { Accessibility }\end{array}$ & $\begin{array}{l}\text { (C. McInerny, 2000; M. Azuma, 2002; G. } \\
\text { Costagliola and F. Ferrucci; Ourania I. Markaki } \\
\text { et al., 2013; Kathrin Wille et al., 2016; Patricia } \\
\text { Acosta-Vargas et al., 2018; M. Azuma, 2002; } \\
\text { G. Costagliola and F. Ferrucci) }\end{array}$ \\
\hline $\begin{array}{l}\text { Quality Impacting } \\
\text { factors }\end{array}$ & $\begin{array}{l}\text { (Luis Olsina, Guillermo Laffuente et al., 2002; } \\
\text { G. Costagliola et al., 2013) }\end{array}$ \\
\hline $\begin{array}{l}\text { Quality evaluation } \\
\text { approaches }\end{array}$ & $\begin{array}{l}\text { (B.M Subraya et al., 2000; Enruqui } \\
\text { Herrera-Viedma et al., 2006; Ourania I. } \\
\text { Markaki et al., 2013; M. Azuma, 2002; } \\
\text { Paramaresthi Windriyani et al., 2014; } \\
\text { Abduljalil et al., 2011; Pedro Lorca et al., 2017; } \\
\text { Abid Ismail et al., 2016; Islam Elkabani et al., } \\
\text { 2015) }\end{array}$ \\
\hline $\begin{array}{l}\text { Assessment based } \\
\text { on WCAG } 2.0\end{array}$ & $\begin{array}{l}\text { (Windriyani P et al., 2014; Kathrin Wille et al., } \\
\text { 2016; Mohd Isa et al., 2016; Patricia } \\
\text { Acosta-Vargas et al., 2017, 2018; Paramaresthi } \\
\text { Windriyani et al., 2014; Markel Vigo et al., } \\
\text { 2013; Balaji V et al., 2016; Abid Ismail et al., } \\
\text { 2016; Islam Elkabani et al., 2015; Mrinal Kanti } \\
\text { Baowaly et al., 2012;) }\end{array}$ \\
\hline
\end{tabular}

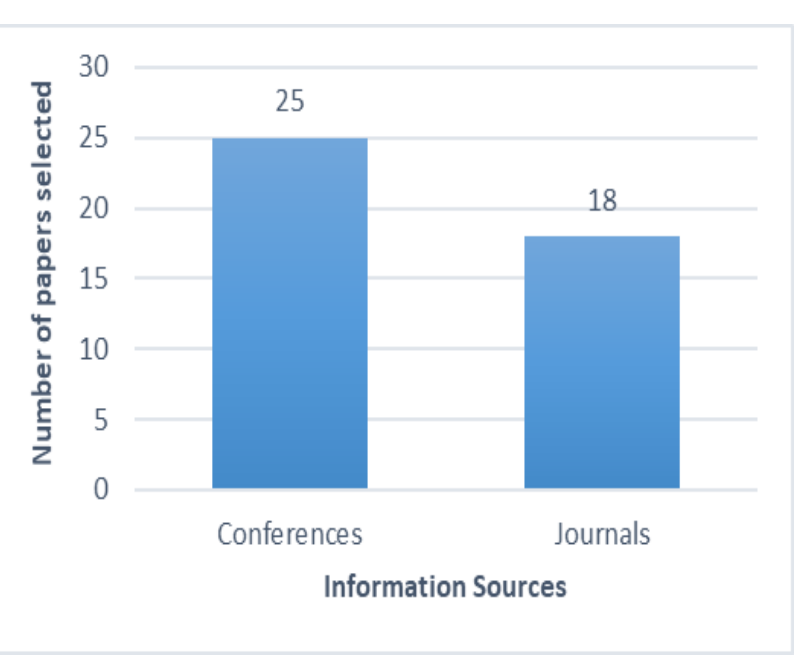

Fig. 2. Information sources for selection of papers 
In this area, the research has considered about 30 published papers from the year 2000 to 2018. It was verified that the assessment was brought by utilizing different automation devices [33-48] and determined the quality after the examination procedure. The outcomes of the relative evaluation are constituted in Table 2 consisting of tools utilized, web sites selected, and degrees of assessment. Numerous existing and preferred assessment tools were used by the authors. The literature has disclosed that a lot of research studies have been executed from previous 20 years on internet accessibility all over the world.

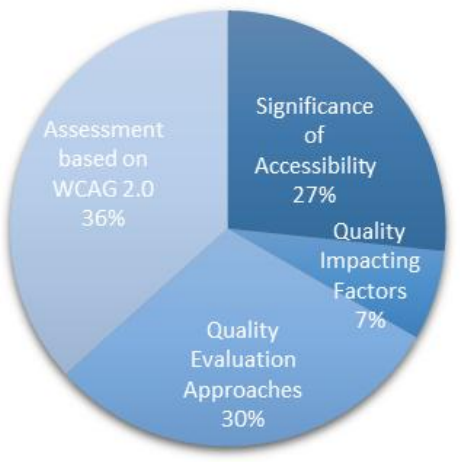

Fig. 3. Distribution of papers selected by research questions

Some scientist utilized computerized website evaluation standards stated by the internet group. Some researches were accomplished to recognize the problems which might impact the efficiency of the content accessibility. Most of the website developers never ever took into consideration the visual impaired individuals and exactly how finest it can be to gain easy access. In a few of the researches, the analysis procedure is straight executed based upon the standards recommended by contrasting website design to suits with the referrals mentioned in WCAG version 2.0. Each resource link has checked with WAVE toolbar and figured out whether any website is going against the standards recommended.

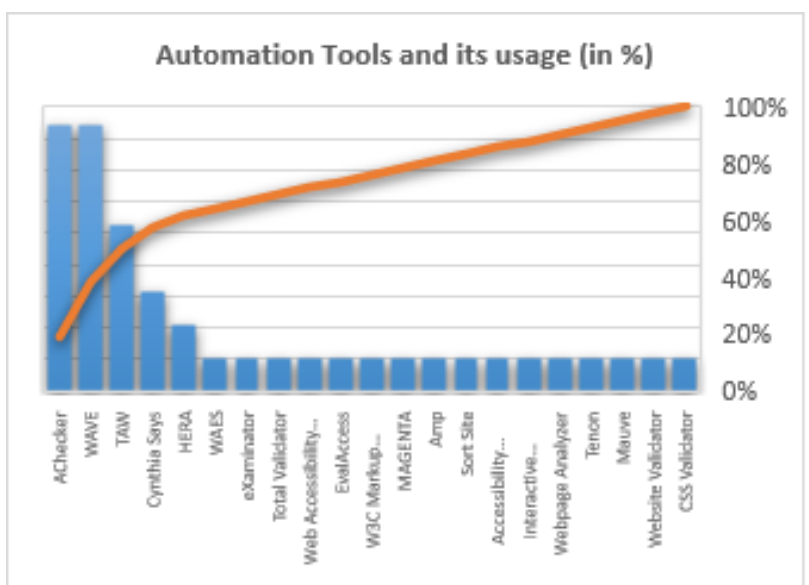

Fig. 4. List of Automation Tools considered in the review

\section{REVIEW METHODOLOGY}

Problem: Identify the publications related to website content accessibility process with respect to usability factors and to assess the need to fulfill the needs. devices to examine the web page of the website versus the

Solution: Evaluation of existing information is needed to determine just how the standards suggested can influence the accessibility and boost the high-quality design so that impairment human can conveniently be viewed.

\section{RESULTS}

This section summarized the results of the review process while giving the answers to the four research questions based on the information extracted from the selected papers.

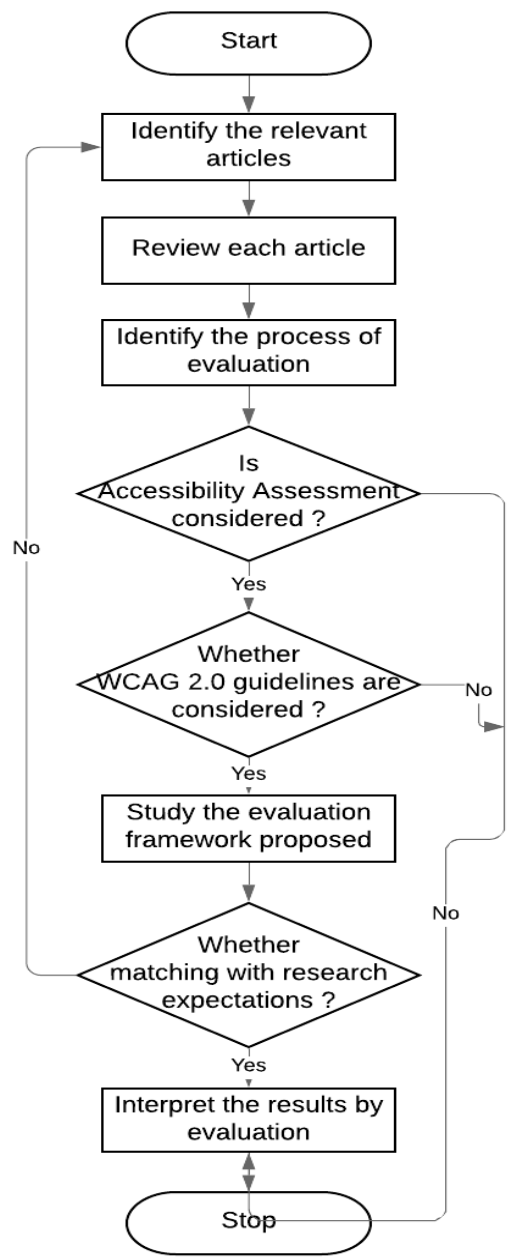

Fig. 5. Flow chart representing the complete process of research

\section{A. Answer to the first question}

The relevance of establishing an easy to use website with a great design and simple accessibility regarding navigating was recognized [1]. The article has recognized specific gaps in design quality with an assistance of modern technology. The Website performance also dealt with a device to analyze and believes regarding accessibility. WWW for Information related systems are extensively utilized by the individuals. Its primary goal is to reduce the error rate by increasing the productivity during their interaction with machines [4]. Keeping this usage insight, the research has recognized the value of interactive solutions to take on the environmental adjustments and modifications in the demand. It is so important to adopt methods to evaluate usability with essential variable before the deploying the application [5].

Published By:

Blue Eyes Intelligence Engineering 
The research study highly thought that any type of website needs to be made by adhering to the standards suggested by WC3. Even it was determined that many authorities attempt to keep a high quality of expectations on the internet and maintains assumptions on on-line solutions for their trouble [7]. It is also determining the role of website evaluation while accessing its content by an individual with impairments similarly the other customers [9]. The research [12] explained the value of the internet in individuals' everyday life and exactly how it has reinvented as a key resource of accessing details specifically in universities worldwide. The study [13] has recognized the relevance of incorporating the software program systems as well as its support group with the components of human and the device. The use of a website relies on highest competence levels and with a higher accessibility levels of any internet application [14]. The research highly thought that any kind of website should be created by adhering to the standards advised by WC3.

\section{B. Answer to the second question}

A repository was created with some metrics to examine the evaluation of website content quality [3]. Recommended metrics list was thought about reused mechanism through which more certain website type, standards of assessment based upon solutions, and application advancement treatments. Some aspects were recommended that can be taken into consideration while making certain the high quality of accessibility [14].

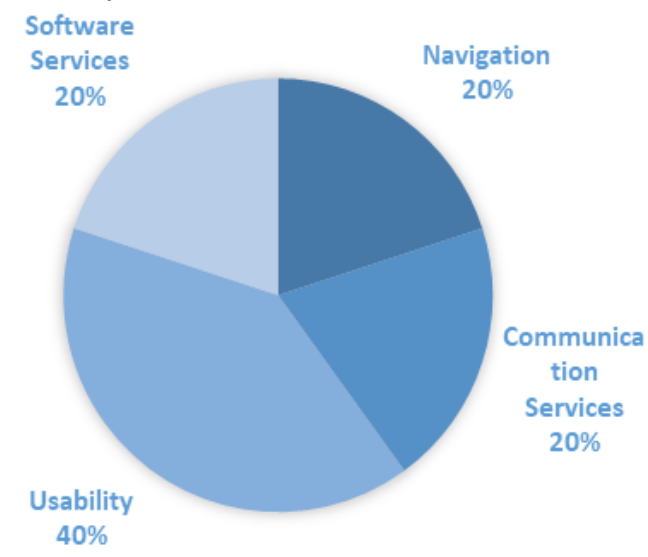

Fig. 6. Distribution of selected papers based on significance levels

\section{Answer to the third question}

The study [2] has determined and recommended an enforcement model to evaluate the content quality by incorporating the user perceptions by protecting its modulation. The procedure of high-quality examination is to make guaranteed that the quality is gauged regarding functionality, design and accessibility standards.

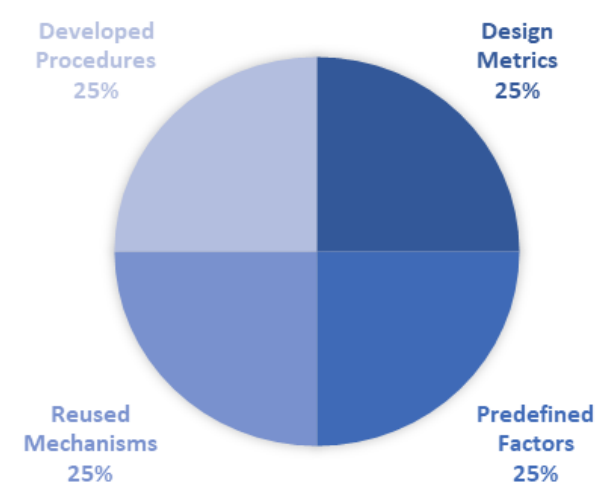

Fig. 7. Distribution of selected papers based on influencing factors

The study [6] has suggested and established a fuzzy model for computation to analyze the information and examine with two significant parts. The initial element is to review the website as well as examine regarding both linguistic and technological suggestions. The second element is assessment with user experience and creates certain tips based upon the reasoning of the user with the linguistic examination. It was examined and specified that the existing assessment techniques are not as per the expectations [7]. A three-layered style for details accessibility is established by incorporating the selected support group with the advancement and operating system [13]. The architecture is human specific and software program metrics that can affect the evaluation of website accessibility examination. The research study has suggested a modular technique where the obstacle can be gotten over with a triangular unclear number. An attempted to enhance the webometrics as well as to boost the university websites regarding both non-technical and technological variables [16]. The study is accomplished a logical procedure to review website accessibility regarding user-centric design, online study, dispersed study to ensure that they can determine the human variables while accessing [17]. A comparative web accessibility testing could be the criteria to measure the accessibility issues with respect to various evaluation methods [18]. A theoretical based assessment relative to content high quality was brought with respect to their accessibility degree [19]. It has taken into consideration internet sites of 19 poly technique and 40 university websites of Portugal and determined some usual checkpoint mistakes in the procedure of internet content accessibility examination [21]. The study [22] was taken on both measurable and qualitative method for functionality analysis as well as ultimately contrasted the outcomes obtained by the tools taken into consideration.

\section{Answer to the forth question}

It came to be compulsory to know the service perspective of every website. Webometrics is among the locations which can be utilized to enhance the quality of accessibility by enhancing the website position. Some universities have assessed just how to boost site quality by thinking about the nontechnical location of WCAG criteria for better standards [8]. 
It has been established that every internet content should accomplish the requirements stated by the internet content accessibility with standards of WCAG 2.0 for an individual [9]. Later, the research recommended a technique to gauge the implementation, compute the application, and reviewed whether the internet content can satisfy the success standards. It was explored the Malaysian web sites to a specific duration in 2014 by utilizing AChecker tool and W3C Accessibility Guidelines [10]. The research study has recognized six significant accessibility problems regarding non-text content, details as well as organization, the objective of web links, language of a web page, as well as tags. Almost 51 e-governing Turkey websites has analyzed with several parameters based on guidelines and standards [11]. The research has thought about the evaluation methodology for website accessibility. It has determined that much of the Latin America academic web sites does not fulfill the website accessibility standards [12]. The Webometrics and WCAG are both standards thought about for examination of internet sites and located variants in their monitoring in non-technical as well as technological elements [16].

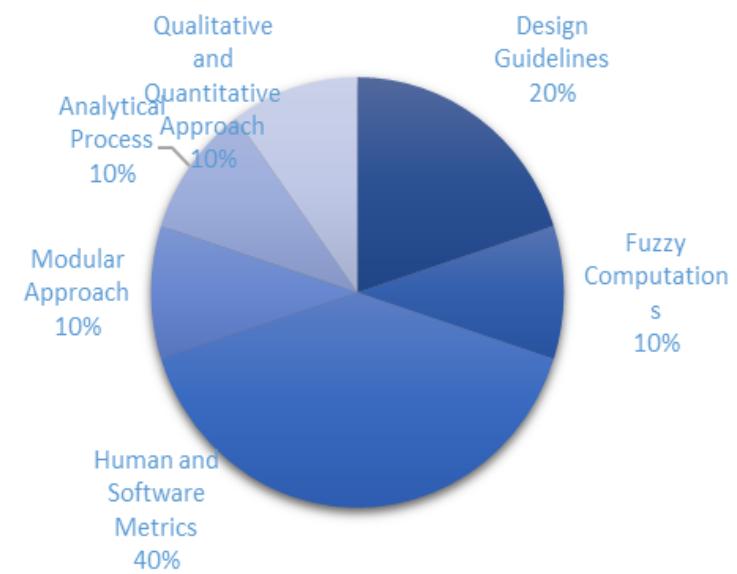

Fig. 8. Distribution of selected papers based on evaluation approaches

The assessment procedure was executed with the online available tools and determined just $23-50 \%$ of the sites covered under no guideline's violations. Accessibility was executed with Accessibility Scanner mobile-based application owned by Google [20]. The study has examined different classifications of mobile applications with success requirements offered in stipulated guidelines. The research also highlighted numerous often taking place accessibility mistakes as well as later recommended to enhance the accessibility approval degrees. The confirmation of WCAG was framed to inspect the accessibility utilizing existing on the internet tools [21]. The research study assessed an open-source internet accessibility assessment device to confirm the web page conformity with WCAG [22]. It was examined the accessibility of e-govern internet sites of Bangladesh as per guidelines [23]. The whole procedure is executed with the available online devices and later suggested certain recommendation to obtain a higher degree of accessibility for their sites.

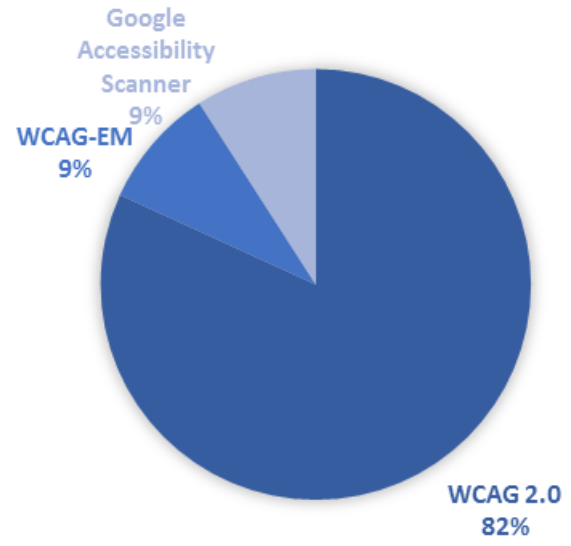

Fig. 9. Distribution of selected papers based on WCAG 2.0 guidelines

\section{DISCUSSIONS}

An overall of 15 articles associated with the website accessibility was taken into consideration for the research study. Then, comparative evaluation is made based upon their methods as well as analysis treatments. The efficiency analysis was carried out via TAW and AChecker tools [23]. The TAW online tool has generated even higher rate of accessibility errors than automated AChecker tool. Only 10\% of the Libyan Federal government websites fulfill the assessment approval standards were observed. The examination was carried out via the AChecker automated tool and determined that just 5\% of Finland country college web sites satisfy the WCAG 2.0 standards [24]. It has carried out examination via AChecker and WAVE tool has observed that just $15 \%$ of Malaysian country sites fulfilled the W3C approval standards [25]. Several literatures are prominent where $5 \%$ of the documents have considered their very own analysis devices like Interactive Evaluation.

\section{A. Usage levels of automated tools}

Several online tools have been used by the researchers to evaluate the websites and assess its quality based on WCAG 2.0 guidelines. It has been observed that $42 \%$ of the considered papers used AChecker, 26\% of TAW and WAVE 2.0, 16\% of WAVE 1.0 and Cynthia Says, 11\% of Hera, 5\% of WAES, eXaminator, MAGENTA, Amp, Sort site, Total Validator, Eval Access, W3C Markup Validator, Accessibility Analyzer, Webpage Analyzer, Website Validator, Tenon, Mauve, and CSS Validator.

\section{B. Country-Wise acceptance levels with WCAG 2.0}

The research study [26] carried out analysis based upon the changed KWCAG 2.0 standards with overall 13 standards and other 20 demands. Just $16 \%$ of the Korean internet sites are fulfilling the accessibility requirements as per the study. In [27], 12 online tools were used and identified that various tools generated various error results. Internet Accessibility tools generated the greatest variety of 2048 errors and HERA automated tool produced the most affordable variety of 48 errors. The examination was performed based upon AChecker, WAVE, 
and Webpage Analyzer tools and recognized a substantial error count of 375989 completely [28]. In [29] the analysis procedure was done based upon the on-line examination tools and recognized that $50 \%$ and above of the Portuguese real estate internet sites are identified with WCAG errors. The [30] carried out an assessment procedure based upon TAW logical tool and determined 15023 variety of degree 3 level of errors. The [31] has performed a hand-operated procedure of examination with 61 human individuals. Everyone has provided 5 jobs and observed their tasks with their degree of accessibility. The research has observed that just $10 \%$ of Liechtenstein district sites are fulfilling the accessibility standards. The research [32] has taken consideration of TAW and Cynthia Say automation devices were made use of for examination and determined that just $66.67 \%$ of the internet sites are just satisfying the accessibility assessment standards.

\section{CONCLUSION}

The standard of the present work is to have a deep study of the existing research activities in evaluating the website accessibility in terms of its content. The review of literature has brought a good knowledge on how the existing research was done, the various approaches implemented to assess the internet sites based on accessibility and how far they are suitable to improve the efficiency. The study also becoming useful to identify whether a website is following the Web Consortium guidelines and people with several disabilities can able to access its content without the issues. In some of the studies, it was observed that the evaluation process was performed on the guidelines by comparing the existing website design with the recommendations. Finally, it was concluded that still more research must be carried out to improve the accessibility for disabled persons.

\section{REFERENCES}

1. C. McInerny," Establishing and maintaining trust in online systems in Book Establishing and maintaining trust in online systems, Series Establishing and maintaining trust in online systems", Editor ed.^eds., City, 2000, pp. 257-270.

2. P Chitti Babu, K C R Bharathi, J Shaik Mohamed, "New Model for E-Business Performance Testing”, i-manager's Journal on Software Engineering, Vol. 8, No. 1, 2013, pp.35-41.

3. Luis Olsina, Guillermo Laffuente and Oscal Pastor, Argentina, "Towards a Reusable Repository for Web Metrics", Journal of Web engineering 1(1), 2002, pp. 61-73.

4. Maria Spichkova, Huai Liu, Mohsen Laali, and Heinz W. Schmidt, "Human Factors in Software Reliability Engineering", WAHESE '15, 2015, pp.1-4.

5. Maristella Matera, Francesca Rizzo, Giovanni Toffetti Carughi, "Web Usability and Accessibility", Journal of Web Engineering, 2008, pp.257-296.

6. Enruqui Herrera-Viedma, Antonio G. Lopez-Herrera and Carlos Porcel, "Evaluating the information quality of Web sites: A methodology based on fuzzy 296 computing with words", Journal of the American Society for Information Science and Technology, Volume 57, Issue 4, 2006, pp.538-549.

7. Ourania I. Markaki, Dimitris E. Charilas; Dimitris Askounis, "Application of Fuzzy Analytic Hierarchy Process to Evaluate the Quality of E-Government Web Sites", 7th International Conference on e-Commerce in Developing Countries with focus on e-Security 2013.

8. P. Windriyani, R. Ferdiana, W. Najib, “Accessibility evaluation using WCAG 2.0 guidelines webometrics-based assessment criteria (case study: Sebelas Maret University)", International Conference on ICT for Smart Society (ICISS) Bandung, 2014, pp. 305-311.

9. Kathrin Wille, Reiner R. Dumke, Cornelius Wille, "Measuring the Accessibility Based on Web Content Accessibility Guidelines", IEEE Explore Joint Conference of the International Workshop on Software
Measurement and the International Conference on Software Process and Product Measurement (IWSM-MENSURA), 2016.

10. Wan Abdul Rahim Wan Mohd Isa, Ahmad Iqbal Hakim Suhaimi, Nadhirah Ariffin and Nurul Fatimah Ishak, "Accessibility Evaluation Using Web Content Accessibility Guidelines (WCAG) 2.0", IEEE Explore in 4th International Conference on User Science and Engineering (i-USEr), 2016, pp.no 1-2.

11. Yakup Akgül, , "Quality evaluation of E-government websites of Turkey", 11th Iberian Conference on Information Systems and Technologies, 2016, pp.1-8.

12. Patricia Acosta-Vargas, Tania Acosta, AND Sergio Lujan-Mora," Challenges to Assess Accessibility in Higher Education Websites: A Comparative Study of Latin America Universities", IEEE Access, Volume 6, 2018, pp.36500 - 36501.

13. M. Azuma, "Software metrics and human factors for WIBIS (WWW and Internet based information systems)", Proceedings First IEEE International Conference on Cognitive Informatics, 2002.

14. Patricia Acosta-Vargas, Sergio Luján-Mora, Luis Salvador-Ullauri, "Quality Evaluation of Government Websites", Fourth International Conference on eDemocracy \& eGovernment (ICEDEG), 2017, pp.8-14.

15. Ourania I. Markaki; Dimitris E. Charilas; Dimitris Askounis, "Application of Fuzzy Analytic Hierarchy Process to Evaluate the Quality of E-Government Web Sites", 7th International Conference on e-Commerce in Developing Countries with focus on eSecurity, 2013.

16. Paramaresthi Windriyanil, Ridi Ferdiana, Warsun Najib, "Accessibility Evaluation Using WCAG 2.0 Guidelines Webometrics Based Assessment Criteria (Case Study: Sebelas Maret University)", IEEE Explore of International Conference on ICT for Smart Society (ICISS), 2014.

17. Sami Abduljalil, Dae-Ki Kang, "Analysis of human factors in software application design for effective user experience”, IEEE Explore 13th International Conference on Advanced Communication Technology (ICACT2011), 2011.

18. Giorgio Brajnik, "A Comparative Test of Web Accessibility Evaluation Methods", Proceedings of the $10^{\text {th }}$ International ACM SigAccess Conference on Computers and Accessibility, 2008, pp. 113-120.

19. Pedro Lorca, Javier De Andre' s, and Ana B. Martı'nez, "The Relationship Between Web Content and Web Accessibility at Universities: The Influence of Social and Cultural Factors", SAGE Publication Journal "The Impact of Social and Cultural Factors", 2017.

20. V. Balaji and K.S. Kuppusamy, "Accessibility Analysis of e-governance Oriented Mobile Applications", IEEE Explore International Conference on Accessibility to Digital World (ICADW), 2016.

21. Abid Ismail, K.S. Kuppusamy, Sara Paiva, “Accessibility Analysis of Higher Education Institution Websites of Portugal”, Universal Access in the Information Society, 2019, pp. .

22. Islam Elkabani, Lama Hamandi, Rached Zantout, Simar Mansi, "Toward Better Web Accessibility", IEEE Explore 5th International Conference on Information \& Communication Technology and Accessibility (ICTA), 2015.

23. Nuha Awlad Karaim, Yavuz Inal, "Usability and Accessibility Evaluation of Libyan Government", International Journal of Universal Access in the Information Society, Springer-Verlag, 2017, pp.4-9.

24. Rita Ismailova, Yavuz Inal, "Accessibility Evaluation of Top University Websites: A Comparative Study of Kyrgyzstan, Azerbaijan, Kazakhstan and Turkey", International Journal Universal Access in the Information Society, Springer-Verlag, 2017, pp.2-8.

25. $\mathrm{Ku}$ Azhar $\mathrm{Ku}$ Saud, "Web Accessibility Initiatives in Malaysian Academic Libraries: Enthusiasm and Challenges", International Conference on Library and Information Science, 2017, pp.6-14.

26. Yakup Akgul, Kemal Vatansever, "Web Accessibility Evaluation of Government Websites for People with Disabilities in Turkey", Journal of Advanced Management Science, Vol.4, No.3, 2016, pp.203-208.

27. Swikruti Dongaonkar, Ramkrishna Vadali, and Chandrakant Dhutadmal, "Content Accessibility Evaluation of Government Website using WCAG (Web Content Accessibility Guidelines)", International Conference on Research in Intelligent and Computing in Engineering, 2017, pp.28-30. 
28. Leandro Coelho Serra, Lucas Pedroso Carvalho, Lucas Pereira Ferreira, Jorge Belimar Silva Vaz, Andre Pimenta Freire, "Accessibility Evaluation of E-Government Mobile Applications in Brazil”, International Conference on Software Development and Technologies for Enhancing Accessibility and Fighting Info Exclusion (DSAI), 2015, pp.351-357.

29. Ramiro Goncalves, Jose Matins, Frederico Branco, "A Review on the Portuguese Enterprise Web Accessibility Levels - A Website Accessibility High Level Improvement Proposal", International Conference on Software Development and Technologies for Enhancing Accessibility and Fighting Info Exclusion (DSAI), 2013, pp.179-182.

30. Trinidad Dominguez Vila, Elisa Alen Gonzalez, and Simon Darcy, "Website Accessibility in the Tourism Industry: An Analysis of Official National Tourism Organization Websites around the World", Disability and Rehabilitation, 2017, pp.1-5.

31. Sven Schmutz, Andreas Sonderegger, and Juergen Sauer, "Implementing Recommendations from Web Accessibility Guidelines: Would They also provide Benefits to Nondisabled Users", Human Factors and Ergonomics Society, 2016, pp.614-615.

32. Veronica Segarra-Faggioni, and Jorge Campoverde, "Evaluation of the Web Accessibility of University Web Portals. Case Study: Universidad Technica Particular de Loja", Association for Computing Machinery, 2017, pp.203-205.

33. Web Accessibility Checker. (2011). [online]. Available: https://achecker.ca/checker/index.php

34. Web Accessibility Evaluation Tool (WAVE). (2018). [online]. Available: https://wave.webaim.org/

35. World Wide Web Consortium (W3C). (2016). [Online]. Available: http://examinator.ws/

36. TAW Web Accessibility and Standardization Services. (2016) [Online]. Available: https://www.tawdis.net/

37. Accessibility validator. (2016). [Online]. Available: https://www.totalvalidator.com/

38. Web Accessibility Evaluation (Eval). (2016). [Online]. Available: http://sipt07. si.ehu.es/evalaccess2/

39. Web Content Error Identification (Cynthiasays). (2016) [Online]. Available: http://www.cynthiasays.com

40. Web Document Markup Validator Checker (2013). [Online]. Available: https://validator.w3.org/

41. Inspection-based Evaluation Tool (Magenta) (2006). [Online] Available: http://giove.isti.cnr.it/accessibility/ magenta

42. Web Accessibility for Preliminary Automatic Analysis. (2013) [Online]. Available: http://www.sidar.org/recur/aplica/ heraffx.php

43. AMP (Accessibility Management Platform). (2018). [Online] Available: https:// www.levelaccess.com/products/software/amp/

44. Website Analyzer (2018). [Online]. Available: http://www.powermapper.com / products/SortSite/

45. Accessibility Checker. (2015). [Online]. Available: https://cksource.com/ckeditor/ services \# accessibility - checker

46. Web Content Accessibility Testing (2013). [Online]. Available: http://www.tenon.io

47. MAUVE Accessibility Validator. (2017). [Online]. Available: http://mauve.isti.cnr.it

48. Web Accessibility validator. (2014) [Online]. Available: http://www.css-validator.org/

\section{AUTHORS PROFILE}

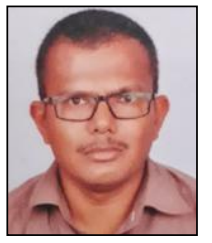

M Nagaraju received his M. Tech in Computer Science and Engineering from JNTU, Hyderabad in 2012, the MSc in Computer Science from Osmania University, Hyderabad in 2004. He is currently a research scholar in Lovely Professional University, Phagwara. His research interests include Web Mining, Internet of Things, and Deep Learning.

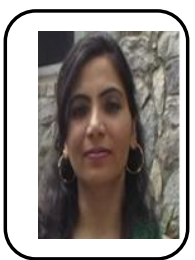

Dr. Priyanka Chawla is doctorate from the Thapar University, Patiala, India. She is presently working as Professor in Lovely Professional University, India. Her active research areas include cloud computing, big data analytics, evolutionary algorithms and software engineering. She has been involving in research for more than 14 years. She has published more than 30 research papers in reputed peer-reviewed international journals. 